\title{
4
}

\section{Implications of the Technology Race}

\author{
Jackson Barkstrom
}

\section{What Is the Technology Race; Why Is It Important?}

Current tensions between the US and China center around a race for technological supremacy and this technological race raises the stakes for all investors: it increases investment risk and requires further analysis on potential impact and opportunity. Let's call this the "tech race." In this chapter, we underline the basic dynamics and reliances between the US and China, gauge the current and future scope of what is likely to be a constantly unfolding tech race and point out opportunities for investors that might arise in China within the near future.

In short, if the US-China tech race escalates, it could immediately handicap many Chinese businesses and hurt US-China collaboration. Global climate change cooperation could suffer as a result. However, as China and the US race to out-compete each other, the tech race may also provoke flurries of innovation in areas such as information technology, clean energy and biotech. The tech race will prove critical for investors because they can and should have a direct role in improving currently insufficient US-China collaboration as well as utilizing newer tech race-driven innovation.

C. Krosinsky, Modern China, https://doi.org/10.1007/978-3-030-39204-8_4 


\section{Dynamics and Reliances \\ of the US-China Relationship}

\section{Fighting While Embracing}

The US and China are not only each other's biggest rivals; they are each other's most important trade partners. Their rivalry combined with their trade reliance makes for a complicated relationship. President Xi refers to the US-China relationship as fighting while embracing (chán dòu), and this metaphor is apt because the US and China constantly balance between hostility and cooperation. Trade, for example, teeters between open trade and protectionism.

\section{Rivalry}

The stakes of the US-China rivalry rise as China pushes to become a global technological leader. The US wants to maintain its current technological and economic advantages over China, and it shields certain technologies from China and pressures China economically in order to hold onto these advantages.

For both security and economic reasons, the US government fears China getting advanced technology, especially regarding semiconductors or cybersecurity. This rivalry dynamic hurts both countries. The US economy grows more slowly with a lack of adequate trade and collaboration, and China suffers severely under US pressure because China currently depends on the US and global markets for supplies as well as for financing.

\section{Reliance}

The US and China depend on each other because each country has different strengths. China has cheap manufacturing, a rapidly developing consumer economy with a high demand for mobile phones and internet-related products and services and a large number of STEM graduates. The US has leading technology, a mature consumer economy and excellent access to global financial markets.

The two countries gain significantly from cross-border trade and investing as well as collaboration opportunities directly because of their different strengths and weaknesses, so much so that they have developed varying degrees of reliance on one another. The US currently relies on China and other countries for most low-cost manufacturing, and China currently relies on the US and other countries for most advanced technology. 


\section{Chinese Reliances and Risks: Foreign Technology Supply and Financing}

China relies on the global supply of advanced technologies, and this reliance makes China especially vulnerable to US policy. For example, when the US restricted Huawei from using Google's Android operating system on its phones, Huawei suffered losses and had to scramble to build its own operating system to make the phones work again.

Semiconductors, which most know as integrated circuits or computer chips, are China's most pressing supply risk. Semiconductors perform the core processing of phones, computers, smart cars, and so on-you cannot make such devices without them-and these chips are China's Achilles' heel because the US, Taiwan, Korea, Japan and Europe are the only areas in the world capable of designing and manufacturing the most advanced semiconductors, that is, microprocessors (VerWey, July, 2019a). China comprises over half of the global semiconductor demand, but domestic Chinese firms can meet only around 30\% of this demand ("China Inside" 2018).

China has plans for future large-scale semiconductor manufacturing, but experts say these efforts will not see success for over ten years due to factors such as lacking human capital (VerWey, August, 2019b). At least for the short term, China will likely rely on global semiconductor supplies to put together most technology. Chinese firms stockpile foreign semiconductors to mitigate this reliance risk, but China remains highly vulnerable to changes in global semiconductor supply (Fig. 4.1).

In addition to China relying on foreign technology such as semiconductors, China relies on a US-dominated global financial system to access capital and conduct international business. A discussion of this reliance is beyond the scope of this chapter, but it is worth noting that the US could potentially use its financial hegemony to put China under great economic pressure (Gewirtz 2019). China may well work to escape this financial reliance.

\section{US Reliances and Risks: Chinese Manufacturing}

Many American firms use Chinese manufacturers and would take years to shift manufacturing from China to another country. Apple is a prime example of this reliance: about $50 \%$ of its supplier locations are in China, and if Apple moved away from China it would lose significant market share to competitors such as Samsung (Reed 2019). At least in the medium term, many American firms will rely on China to compete globally. It's also important to note that 


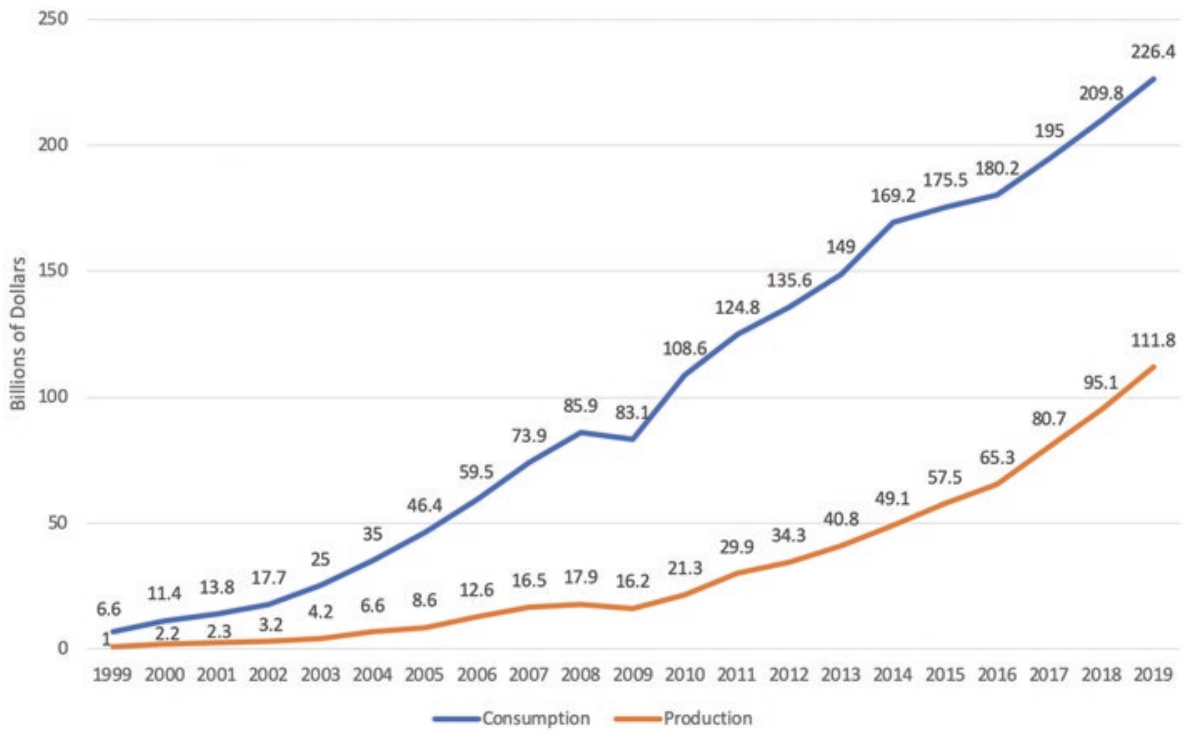

Fig. 4.1 Chinese semiconductor consumption and production by value. (Source: PwC, "China's Impact on the Semiconductor Industry: 2017 Update," November 2017. Data after 2015 is projected)

the China-controlled rare earth element supply is not a major risk to the US. Evidence suggests that a Chinese rare earth element ban would do little more than raise prices of consumer electronics (Hsu 2019). The US can both cut back on rare earth usage and step up rare earth production, whereas China cannot cut back on semiconductor usage or produce the most advanced semiconductors without serious difficulties.

\section{Present and Future Scope of the Technology Race}

\section{Rivaling Goals of the US and China}

Arguably, the US wants to hold a comprehensive technological and economic advantage over China, while China in response wants to build a self-reliant technological ecosystem near or above the level of the US. 


\section{A Rivalry Focused on Technology and Economics}

The present conflict between China and the US surrounds technology and economics - headlines focus on tariffs and Huawei contracts, not occupations and annexations - and it's a conflict of which country can develop the best technology and the most powerful economic ecosystem. Niall Fergusson called the US-China relationship the "New Cold War" in a recent editorial in the New York Times, but as of now Cold War comparisons seem to be more provocative than meaningful. Although one could argue that the leader of either country might use such a conflict for political gain, the US-China conflict is certainly not a political conflict on the level of what was the US versus USSR Cold War.

Information technology development is central to the tech race because it allows countries to gain reliance advantages. Consider 5G: China is a global leader in 5G development and regulation, and Huawei collaborates on 5G industry standards and makes leading $5 \mathrm{G}$ technology at a lower price than any competitor (Thomas 2019).

With its clear competitive advantage, Huawei gets contracts from all over the world in spite of US pressure, and thus many countries rely on Huawei networks. This is a Chinese reliance advantage: countries with Huawei networks rely on Huawei networks to perform and carry their communications. This shouldn't come as too much of a shock: yes, certain countries rely on Huawei networks despite the US's best efforts, but certain Chinese industries also rely on the foreign supply of semiconductors despite China's best efforts. The US currently has many reliance advantages over China that China seeks to eliminate.

\section{Long-Term Chinese Self-Reliance Could Raise the Stakes}

China pushes for longer-term technological self-reliance, including the ability to manufacture advanced semiconductors, and these Chinese self-reliance efforts may raise the stakes for the US-China rivalry and for investors. Despite this possibility, some industry experts believe that US-China relations will improve. Fortune's November 2019 Global Tech Forum in Guangzhou, for example, was filled with optimistic perspectives including a Chinese professor who said the entire US-China conflict was rooted in misunderstanding ("Inside the Trade" 2019). The tech race may be a misunderstanding, or it could get worse. 
A self-reliant China could decouple from the West and develop its own forms of internet structures, city structures, cybersecurity, and so on, on a level never seen before. This decoupling would increase political risk as well as opportunity. Decoupling in general increases risk for two reasons: First, decoupling leads to less communication between two sides, and less communication increases misunderstanding and risk of conflict. Second, decoupling in some scenarios gives one side an opportunity to dominate the other side without negative consequences. Take this example: if rival countries $\mathrm{A}$ and $B$ operate with two completely different $R \& D$ pipelines for supercomputers, and A develops an incredibly powerful supercomputer that's years ahead of B, A could potentially sabotage its rival's computer infrastructure with little repercussion (Denning 2019). US-China decoupling, however, also increases opportunity. Investors can combine the best developments from the "China model" and the "US model" and potentially add significant value. As collaboration decreases, the potential value of future collaboration could actually increase.

China may decouple more comprehensively from the West if it achieves more self-reliance. Evidence supporting decoupling includes China's historical emphasis on its uniquely Chinese development models. For example, in 2001, President Xi published an article discussing development economics in China, and in the words of China expert Andrew Batson, "this article could not be a clearer statement of the view that China's model will not and cannot converge with that of Western developed countries" (2019). Additionally, China currently exports its methods of internet censorship and surveillance to other countries (Dave 2018). Evidence opposing decoupling includes plentiful international opportunities for Chinese business, especially in Europe where China already has well-established business networks. We believe China will try to get the best of both worlds and pursue a balanced path between ideological independence and economic opportunity, but this belief assumes a continuation in the current Chinese leadership strategies.

\section{Chinese Innovation Strategy and Sector Outlooks}

\section{China's Innovation Strategy of Self-Reliance and Global Leadership}

Chinese innovation strategy often aims government intervention at specific sectors, and focuses on (1) developing Chinese self-reliance via initiatives such as semiconductor manufacturing and (2) developing Chinese global leadership 
via supporting globally important technologies—that is, China's direct and indirect government support of Huawei (Yap 2019)—or via supporting globally underdeveloped technologies such as clean energy or electric vehicles (Naughton 2018, pp. 380-382). Chinese policies focus on both achieving self-reliance and achieving global leadership. China has consistently increased its support for these development policies since they began in 2006 (ibid.).

It's important to note that Chinese innovation policy not only focuses on large and important technological sectors such as semiconductors and artificial intelligence. It also focuses on underdeveloped sectors with no dominant global firms such as electric vehicles, renewable energy and smart cities in order to give Chinese firms a competitive advantage over the rest of the world (ibid.). Leading sustainable technology, for example, could help Chinese firms gain a competitive advantage in sustainability-conscious European markets.

\section{Sector Outlooks}

\section{Clean Energy}

The Chinese clean energy sector will depend heavily on future Chinese government policy, and future government policy remains unclear (Baxter and Zhe 2019). China heavily supported clean energy from 2016 to 2020 via the 13th Five Year Plan and could still use clean energy for its own pollution problems as well as for business opportunities in Europe. However, a defensive China may also use its abundant coal supply to lessen its reliance on foreign oil, and China has signaled recently that it could increase its coal production and decrease its commitment to sustainability in response to rising global tensions (Wu 2019). The 14th Five Year Plan (2021-2025) will clarify China's position on clean energy.

\section{Biotech}

The tech race implications for biotech remain unclear. It remains to be seen if the US will view China's biotech sector as a national security risk and respond with damaging policy (Rapoza 2019), but China is a fertile ground for future biotech innovation, and there is potential for US-China collaboration due to China-specific advantages. For example, China has relatively loose rules for assembling medical datasets and potentially looser rules for experimental therapies ("China's Curing Cancer" 2019). China is also trying to establish medical regulations up to par with peers such as the US, and these regulations would 
further improve the related investing environment (ibid.). Investors can capitalize on the newest developments in the US and China: an unprecedented Chinese medical dataset, for example, could be shared globally. Solutions to the novel coronavirus outbreak and any further similar outbreaks could also be more rapidly enabled through increased global cooperation.

\section{G and the Internet of Things (IoT)}

Political tensions may continue to rise as the US struggles to come up with an answer to Huawei's dominance. The short-term future of $5 \mathrm{G}$ and IoT may well be dominated by Huawei-as mentioned earlier, Huawei's $5 \mathrm{G}$ is robust and capable and in addition to 5G, Huawei is building Io T "smart factories" with advanced sensors as well as writing IoT industry standards ("Huawei Founder Predicts" 2019).

For those who don't know, IoT essentially means objects communicating with each other, and an IoT "smart factory" is roughly analogous to a kitchen with appliances that could communicate with each other and make a meal with no human intervention. China has an advantage over the US in terms of IoT development because of its relaxed privacy laws as well as the government's direct role in funding innovation. Under the 2016-2020 Five Year Plan China has invested $\$ 74$ billion in "smart city" technology ("How China's Smart-City" 2019), where a city monitors citizens in real time and uses the data not only for surveillance but also to improve efficiency in areas such as transportation, energy usage and emergency response.

IoT brings into question a lot of data privacy and monitoring concerns, but as the technology continues to improve it will enable benign efficiency improvements across many different fields.

\section{Supercomputing and Artificial Intelligence (AI)}

The US and China may continue to restrict cross-border collaboration and increase funding efforts in the fields of supercomputing and artificial intelligence. Companies and investors will have to deal with proprietary technology in these fields carefully. In terms of supercomputing, a cybersecurity disaster will likely not ensue due to one country being better than the other. The US and China are both making some progress regarding quantum computing, but neither country is likely to develop an ultra-powerful computer that can break encryptions (Naughton 2019). Nonetheless, the US and China may still race to develop powerful computers. In terms of artificial intelligence, the 
November 2019 Interim Report from the US Commission on Artificial Intelligence signals that the US is willing to step up funding for AI as well as wall off its AI-related intellectual property from China, and the US and China could be beginning a race for the best AI capabilities. AI completely depends on the data that it's actually using, and for most applications it isn't a magic solution, but American and Chinese governments each have massive stockpiles of data to incentivize AI development.

\section{Manufacturing}

The US and China may both protect and develop their own cutting-edge manufacturing capabilities, especially regarding advanced semiconductor manufacturing and $3 \mathrm{D}$ printing. In terms of semiconductors, China desperately wants to gain semiconductor self-reliance by catching up to the world's most advanced manufacturers, but it remains years behind global leaders (VerWey, August, 2019b). In terms of 3D printing, China wants to use this along with other manufacturing advances to become a leading supplier of high-tech components and equipment (Naughton 2018, pp. 320-322). The US, however, recently included semiconductor and 3D printing technologies in export restrictions (Alper 2019) and does not want China to surpass its own technological capabilities. We could see another race develop potentially between the two countries.

\section{Conclusion}

If the US and China split further from each other, investors who can bridge the gap between countries and choose the best opportunities in either will likely become even more valuable. Thus, as the tech race continues, investors, perhaps especially sustainable investors, working both with and between the US and China can become even more valuable and important as a bridge. Sustainability-minded investors of all stripes can focus on helping advance sectors such as biotech or clean energy that may otherwise fall victim to political conflict, helping enable newly developed technology from both countries to be put to good use.

There are plenty of risks during the current tech race: government policies can change without warning, deals can be blocked and firms can get handcuffed by political worries. However, the tech race should present vigilant investors with worthwhile opportunities. 


\section{References}

Alper, Alexandra. 2019. U.S. Finalizing Rules to Limit Sensitive Tech Exports to China, Others. Reuters, December.

Batson, Andrew. 2019. What Xi Jinping Thinks About Development Economics. Andrewbatson.com, December.

Baxter, Tom, and Yao Zhe. 2019. The 14th Five Year Plan: What Ideas Are on the Table? Chinadialogue.com, July.

China's Curing Cancer Faster and Cheaper than Anywhere Else. 2019. Bloomberg, December.

China's Impact on the Semiconductor Industry: 2017 Update. PwC, November.

China Inside: Chinese Semiconductors Will Power Artificial Intelligence. 2018. Deloitte Insights, December.

Dave, Paresh. 2018. China Exports Its Restrictive Internet Policies to Dozens of Countries: Report. Reuters, November.

Denning, Dorothy. 2019. Is Quantum Computing a Cybersecurity Threat? American Scientist, April.

Gewirtz, Julian. 2019. Look Out: Some Chinese Thinkers Are Girding for a 'Financial War.' Politico, December.

How China's Smart-City Tech Focuses on Its Own Citizens. 2019. Financial Times, June.

Hsu, Jeremy. 2019. Don't Panic About Rare Earth Elements. Scientific American, May.

Huawei Founder Predicts Internet of Things Is Next US Battle. 2019. Financial Times, July.

Inside the Trade War's Tech Battle that Neither China Nor the U.S. Can Afford to Lose. 2019. Fortune, November.

Naughton, Barry. 2018. The Chinese Economy: Adaptation and Growth. Cambridge, MA: MIT Press.

Naughton, John. 2019. Will Advances in Quantum Computing Affect Internet Security? The Guardian, September.

Rapoza, Kenneth. 2019. Next Up in China Trade War: Biotech Purge?, September.

Reed, J.R. 2019. President Trump Ordered US Firms to Ditch China, but Many Already Have and More Are on the Way. CNBC, September.

Thomas, Elise. 2019. Huawei and 5G: What Are the Alternatives? The Strategist, March. Australian Strategic Policy Institute.

VerWey, John. 2019a. Chinese Semiconductor Industrial Policy: Past and Present. United States International Trade Commission Journal of International Commerce and Economics, July. SSRN.

. 2019b. Chinese Semiconductor Industrial Policy: Prospects for Future Success. United States International Trade Commission Journal of International Commerce and Economics, August. SSRN.

Wu, Yixiu. 2019. Is Coal Power Winning the US-China Trade War? Chinadialogue. com, December.

Yap, Chuin-Wei. 2019. State Support Helped Fuel Huawei’s Global Rise. Wall Street Journal, December. 